International Journal of Advanced Engineering and Technology

ISSN: 2456-7655; Impact Factor: RJIF 5.54

Received: 10-06-2019; Accepted: 15-07-2019

www.newengineeringjournal.com

Volume 3; Issue 3; July 2019; Page No. 90-94

\title{
Multi-banking automatic teller machine transaction system by utilizing GSM and biometric identification with one single touch
}

\author{
Muhammad Yasir Imam ${ }^{1}$, Nabila Jannat ${ }^{2}$, Gul Sher Khan ${ }^{3}$ \\ ${ }^{1,2}$ Department. Of Computer Sciences and IT, Alhamd Islamic University, Bhara Kahu, Islamabad, Pakistan \\ ${ }^{3}$ Department. Of Management Sciences, GC University, Faisalabad, Pakistan
}

\begin{abstract}
Everyone in many banks has many types of bank accounts, people need to bring a lot of ATM cards for their transaction, many types of PINs for each account.In the current system, ATM machine user identification systems depend only on bank ATM car ds, safety secret pin code, and also such kind of user ID verification methods which measures are not optimal and sometimes t here are incidents where we dismiss our secret security PIN code, lose ATM cards, rob ATM cards, stolen secret PIN code. Weare presenting a fresh concept or idea for the ATM machine user identification scheme, "Multi-banking Automatic Teller Machine Transaction System by Utilizing GSM and Biometric Identification with One Single Touch" to get control of the issues in the current ATM machine system. On the base of fingerprint identification method which is also one of most secure systems, unofficial accesses are blocked, as it makes fingerprint technique a unique recognition for every user. Our introduced system also assures a very secure GSM and OTP based transaction deals. The presented scheme has no hazard in managing many account transaction deals and performs high-level security, compared to the current ATM machine scheme.
\end{abstract}

Keywords: Security, ATM, PIN, multi-banking, biometric identification and GSM authentication

\section{Introduction}

An ATM is an electronic machine which allows bank account customers to complete their transaction deals at any time without human being involvement. In an Automatic Teller Machine system users verify themselves by utilizing a plastic made card on which magnetic stripe is fixed known as an Automatic Teller Machine card. The magnetic stripe holds information associated to user. Occasionally it occurs that the information on magnetic can be simply ruined by powerful magnetic waves.

About Personal Identification Number, every account has unique PINs in traditional Automatic Teller Machine system sometimes we disremember PINs or losing PIN to someone other. So, the Automatic Teller Machine card have many numbers of disadvantages like smash the card, defeated the card, rob the card, defeated PIN, disremember PINs, etc. due to these problems there are highest probabilities of scams and frauds. Automatic Teller Machine supplies customers $24 \times 7$ services for doing easy transaction deals, but as the usage of Automatic Teller Machine growing in the matching ratio criminals' attacks on the Automatic Teller Machine are also get larger daily ${ }^{[1]}$.

All Automatic Teller Machine Customers always locating to remain their every transaction deal under the well secure observation in the case of financial affairs still sometime security growing many greatest problems, when think about the Automatic Teller Machine, the principle concern is also physical security which focuses on to make sure limitation of access, Identification and Validation ${ }^{[2]}$.

As present Automatic Teller Machine in the market place also having many different drawbacks because of Automatic Teller Machine cards are also made up of the plastic card that have a magnetic strip is fixed for saving of a data similar to details of customers sometime it occurs magnetic strip turn neutral due to the powerful magnetic fields also have other disadvantages as like disremember ours ATM PINs, lose ATM cards, may cards get stolen. Thief make use of unauthorized ATM card readers over authorized ATM card readers to obtain the PIN codes. And cybercriminals also make utilization of unauthorized devices to get the access into the customer bank accounts illegally.

The standard method for banking transaction deal identification of customer which is based upon PIN is growing scanty these days ${ }^{[5]}$.

The Biometric method is based upon customer's physical attribute that is lasting and unique for everyone.

In ${ }^{[6,11]}$ this call for the biometric machines to be fixed in standard Automatic Teller Machine. In Biometric identification fingerprint system is turn into highly popular all over the world. In ${ }^{[7]}$ the singularity of fingerprint of every human being makes the fingerprint identification as the most secure. This stops the unauthorized entry to the bank account of a user. It works as a latch which unlock only if the key is correct i.e. approved fingerprint is found. Biometric identification has been given its correctness because the skin on our hands, feet display a stream positioning of hills on every point of the hand finger which is sole and lasting.

\section{Systematic Literature Review}

A review, as a comparison case study is shown in Table I. It understands the biometric techniques of growing security for transaction deals with Automatic Teller Machine and oth er systems. 
Table 1: Systematic literature review table

\begin{tabular}{|c|c|c|c|c|}
\hline $\begin{array}{l}\text { Sr. } \\
\text { No. }\end{array}$ & $\begin{array}{l}\text { Title of the } \\
\text { Research } \\
\text { Papers }\end{array}$ & Method & Benefits & Drawbacks \\
\hline 1. & $\begin{array}{l}\text { An own } \\
\text { Banking } \\
\text { Biometric } \\
\text { M/C system } \\
\text { with vrong } \\
\text { identificatio } \\
\text { n Applied to } \\
\text { Fingerprint } \\
\text { method and } \\
\text { Iris method } \\
\text { along with } \\
\text { GSM tor } \\
\text { One Time } \\
\text { Password } \\
{[5] \text {. }}\end{array}$ & $\begin{array}{l}\text { GSM } \\
\text { Technolo } \\
\text { gy, } \\
\text { Biometri } \\
\text { c Method } \\
\text { and } \\
\text { RFID }\end{array}$ & $\begin{array}{l}\text { 1. Sure } \\
\text { identifica } \\
\text { tion } \\
2 \text {. Extend } \\
\text { the } \\
\text { security } \\
3 \text {. High } \\
\text { level } \\
\text { correctne } \\
\text { ss }\end{array}$ & $\begin{array}{l}\text { Probably } \\
\text { GSM system } \\
\text { or network } \\
\text { lack of } \\
\text { success } \\
\text { happen }\end{array}$ \\
\hline 2. & $\begin{array}{l}\text { An obstacle } \\
\text { Based } \\
\text { Biometric } \\
\text { plan } \\
\text { Automatic } \\
\text { Teller } \\
\text { Machine and } \\
\text { Swiping } \\
\text { Machine } \\
\text { [13] }\end{array}$ & $\begin{array}{l}\text { (EDC) } \\
\text { Electroni } \\
\text { c Data } \\
\text { Capture }\end{array}$ & $\begin{array}{l}\text { 1.lasting } \\
\text { ness of } \\
\text { sensors } \\
2 . \text { Reliabi } \\
\text { lity and } \\
\text { Security }\end{array}$ & $\begin{array}{l}\text { Time use, } \\
\text { sensor } \\
\text { problem and } \\
\text { noise }\end{array}$ \\
\hline 3. & $\begin{array}{l}\text { Biometric } \\
\text { system in } \\
\text { Human- } \\
\text { Machine } \\
\text { Interaction } \\
\text { [3] }\end{array}$ & $\begin{array}{l}\text { Human- } \\
\text { Machine } \\
\text { interconn } \\
\text { ection } \\
\text { technolo } \\
\text { gy, } \\
\text { decision } \\
\text { taking } \\
\text { methods }\end{array}$ & $\begin{array}{l}\text { 1.Give } \\
\text { decision } \\
\text { taking } \\
\text { system } \\
2 . \text { high } \\
\text { leve1 } \\
\text { correctne } \\
\text { ss }\end{array}$ & $\begin{array}{l}\text { This system } \\
\text { requires to } \\
\text { be sensitive } \\
\text { to folk } \\
\text { dissimilarity, } \\
\text { face } \\
\text { appearance. }\end{array}$ \\
\hline 4. & $\begin{array}{l}\text { An article } \\
\text { technique to } \\
\text { increase the } \\
\text { security of } \\
\text { Automatic } \\
\text { Teller } \\
\text { Machine } \\
\text { utilizing } \\
\text { Biometric } \\
\text { method [26] }\end{array}$ & $\begin{array}{l}\text { Encodin } \\
\text { g and } \\
\text { Decodin } \\
\text { g, The } \\
\text { Blowfish } \\
\text { Algorith } \\
\text { m. } \\
\text { Binaized } \\
\text { images } \\
\text { of tee } \\
\text { fingerpri } \\
\text { nt and } \\
\text { the Gray } \\
\text { scale } \\
\text { image of } \\
\text { the } \\
\text { fingerpri } \\
\text { nt }\end{array}$ & $\begin{array}{l}1 \\
\text { Decreasi } \\
\text { ng the } \\
\text { bandwidt } \\
\mathrm{h} \text { and the } \\
\text { time } \\
\text { needed } \\
\text { for the } \\
\text { transmiss } \\
\text { ion. } \\
\text { 2.Supply } \\
\text { security }\end{array}$ & $\begin{array}{l}\text { recognize the } \\
\text { center points } \\
\text { Image fed } \\
\text { may change } \\
\text { in angle. }\end{array}$ \\
\hline 5. & $\begin{array}{l}\text { Biometric } \\
\text { standard: A } \\
\text { analysis of } \\
\text { fingerprint, } \\
\text { iris } \\
\text { appearance } \\
\text { and face } \\
\text { appearance } \\
\text { [6] }\end{array}$ & $\begin{array}{l}\text { QA } \\
\text { A1gorith } \\
m\end{array}$ & $\begin{array}{l}\text { Powwerful } \\
\text { performa } \\
\text { nce }\end{array}$ & $\begin{array}{l}\text { Generate } \\
\text { more noise }\end{array}$ \\
\hline 6. & $\begin{array}{l}\text { Instinctually } \\
\text { Facial } \\
\text { identificatio } \\
\text { n Automatic } \\
\text { Autler } \\
\text { Meller } \\
\text { Machine } \\
\text { customers } \\
\text { [7] }\end{array}$ & $\begin{array}{l}\text { Magnetic } \\
\text { stripe is } \\
\text { use for } \\
\text { informati } \\
\text { on saving }\end{array}$ & $\begin{array}{l}\text { 1.Inform } \\
\text { ation can } \\
\text { be } \\
\text { changed } \\
\text { if } \\
\text { essential } \\
2 \text {. Iess } \\
\text { expensiv } \\
\text { e }\end{array}$ & $\begin{array}{l}\text { data can be } \\
\text { ruined, } \\
\text { Breakable }\end{array}$ \\
\hline 7. & $\begin{array}{l}\text { Automatic } \\
\text { Teller } \\
\text { Machine } \\
\text { system is } \\
\text { relying on } \\
\text { fingerprint } \\
\text { identificatio } \\
\text { n [8] }\end{array}$ & $\begin{array}{l}\text { Gabor } \\
\text { filter } \\
\text { A1gorith } \\
\text { m and } \\
\text { Direction } \\
\text { filter } \\
\text { A1gorith } \\
\text { m, } \\
\text { Embedde } \\
\text { d } \\
\text { System } \\
\text { mode1, } \\
\text { ARM 9, } \\
\text { GSM } \\
\text { system }\end{array}$ & $\begin{array}{l}\text { 1. } \\
\text { Security } \\
\text { quality } \\
\text { were } \\
\text { increased } \\
2 \text {. } \\
\text { Stability } \\
\text { and } \\
\text { accuracy } \\
\text { of } \\
\text { fingerpri } \\
\text { nt } \\
\text { attributes }\end{array}$ & $\begin{array}{l}\text { Fingerprint } \\
\text { image } \\
\text { occupy a lot } \\
\text { amount of } \\
\text { noise, thus it } \\
\text { consuming } \\
\text { many time }\end{array}$ \\
\hline
\end{tabular}


Table 2: Biometric devices differentiation ${ }^{[16]}$

\begin{tabular}{|l|l|l|l|l|}
\hline $\begin{array}{l}\text { Biometric } \\
\text { Technology }\end{array}$ & correctness & price & $\begin{array}{l}\text { Devices } \\
\text { needed }\end{array}$ & $\begin{array}{l}\text { Socia } \\
1 \\
\text { acce } \\
\text { ptab1 } \\
\text { eness }\end{array}$ \\
\hline $\begin{array}{l}\text { Iris } \\
\text { identification }\end{array}$ & Higher & Expensive & $\begin{array}{l}\text { Camera } \\
\text { Device }\end{array}$ & Low \\
\hline $\begin{array}{l}\text { Facie } \\
\text { identification }\end{array}$ & $\begin{array}{l}\text { Medium to } \\
\text { low }\end{array}$ & Medium & Camera & High \\
\hline $\begin{array}{l}\text { Voice } \\
\text { identification }\end{array}$ & Medium & Medium & Microphone & High \\
\hline Fingerprint & High & $\begin{array}{l}\text { Less } \\
\text { Expensive }\end{array}$ & $\begin{array}{l}\text { Fingerprint } \\
\text { Scanner }\end{array}$ & High \\
\hline
\end{tabular}

There are many methods for Biometric. They mainly include iris technology, face identification, voice identification, Fingerprints, palm technology, signature identification, etc. In our proposed system, we utilize fingerprints method because it gives high correctness, compares with other devices as less expensive.

\section{Problem Statement}

Every human has many kinds of bank accounts in many kinds of banks, customers require to carry many ATM cards for transaction deals, there may be many PINs for each account. Occasionally it happens that we disremember ours PINs, lose our ATM cards, ATM cards may be got rob, rob PINs such outline are faced in our daily life, so to reduce these problems, "Multi-banking Automatic Teller Machine System Utilizing GSM and Biometric Identification with Single Touch" is presented.

\section{Proposed System}

Plan a system which is modify the standard Automatic Teller Machine transaction system by fingerprint-based recognition method and GSM based identification transaction. For the aim of recognition, user fingerprint is needed for identification operation. Each one has unique fingerprint. Thus, due to person fingerprint is alter the traditional Automatic Teller Machine cards and PINs. After successful identification it provides all the bank account list of users and provides permit to execute transactions on the accounts. During the transaction operation a control move to the GSM system to complete an identification transaction from the bank side. This reduce the disadvantages of the existing ATM system with better security.

Objective of presented system -

- High level security-based transactions.

- To give access to many accounts in a single touch.

- Not required to keep multiple ATM cards and PINs.

- Gives many facilities as like intra and interbank transaction deals.

\section{Architecture}

The building design of the presented system shown in Figure: 1. the function of system began with reading the input from customer as a fingerprint of customer. This will be read by the fingerprint scanner. The input from customer will be confirmed from the information saved in the D.B and gets Verified.

The architecture of presented system model is divided into three different operating sets, A) Working of Fingerprint system B) Function of web Services C) Working of GSM system.

The D.B are saved on cloud system. Web services provide access to all bank accounts of customers.

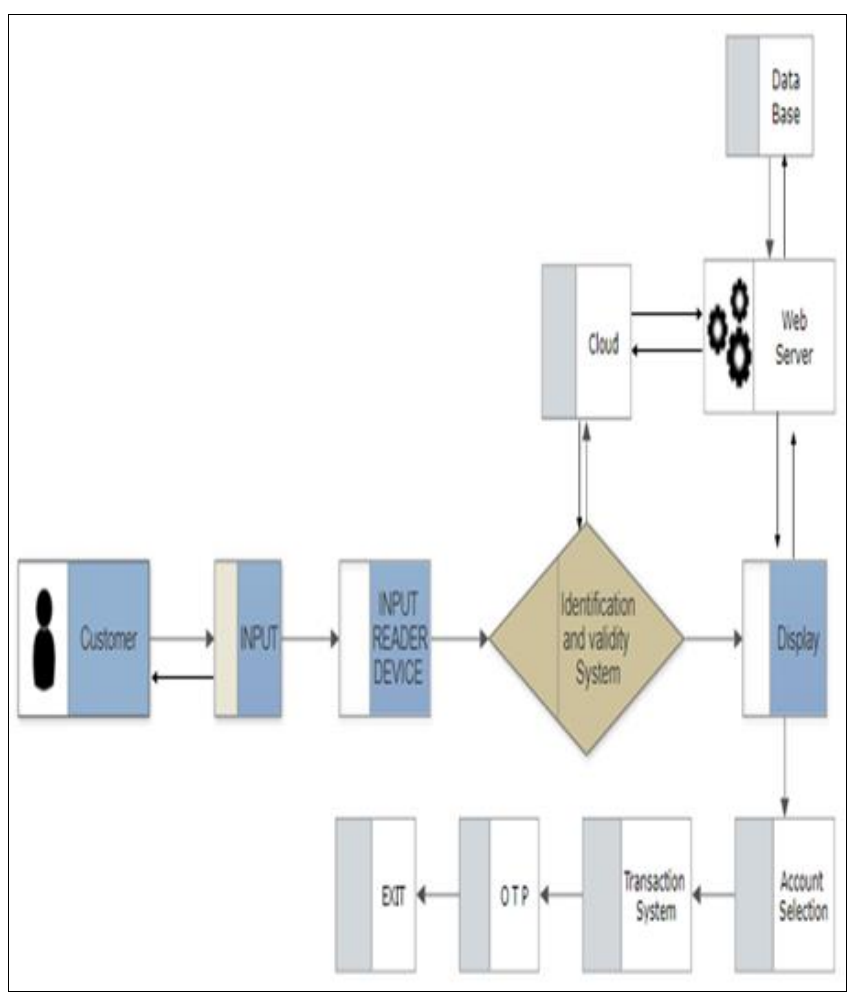

Fig 1: Block Diagram of Presented System

\section{a. Working of Fingerprint System}

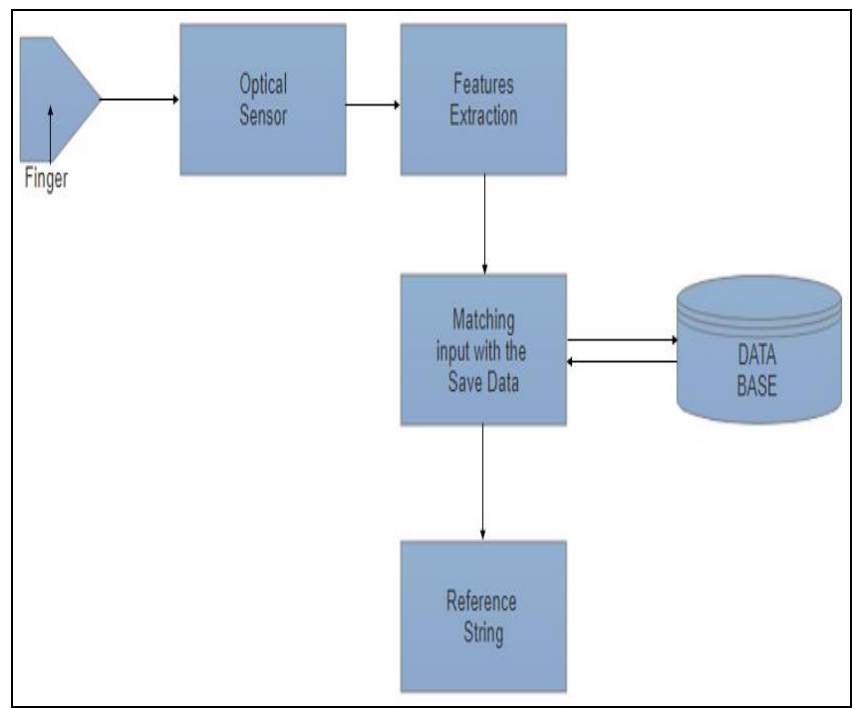

Fig 2: Fingerprint working

Fingerprint scanner device reads the information through the optical (device) scanner sensor and identifies it with the enrolled information in the D.B on the cloud system. If identification is successful it gives a UID. Utilizing UID brings the detail data from bank D.B. In author ${ }^{[8]}$ on cloud system we can securely hold critical information by the utilize of fingerprint this helps to utilize here cloud system. In author ${ }^{[2,9,10]}$ many of the optical scanners utilized the Minutiae Algorithm because it gives high level accuracy.

Fingerprint scanner device utilized for scanning is optical scanner. It mainly performs two works:

- Determines whether the plan of new fingerprint reflection matches the earlier stored reflection.

- Takes image of the fingerprint.

One of the major parts which require to consider, standard 
of the finger reflection. Factors affected to the standard of reflection are

- Sensor states: - Size, Noise, Dirtiness and customers cooperation.

- Skin states: - Wetness, Dryness, Dirtiness, Permanent or Temporary Cuts, etc.

Once the fingerprint is verified the system model requests web services for the bank account details of the customer. The information of all bank accounts of customers are shown for the further transaction deals.

The following table shows the complete information of fingerprint Scanner devices ${ }^{[20]}$

Table 3: Fingerprint scanner devices

\begin{tabular}{|l|l|l|l|}
\hline $\begin{array}{l}\text { Fingerprints } \\
\text { Devices }\end{array}$ & $\begin{array}{l}\text { Devices } \\
\text { used }\end{array}$ & Performance/Working & Cost \\
\hline $\begin{array}{l}\text { Optical } \\
\text { Scanner } \\
\text { Device }\end{array}$ & Scanner & Higher & $\begin{array}{l}\text { Less } \\
\text { expensive }\end{array}$ \\
\hline $\begin{array}{l}\text { Ultrasonic } \\
\text { Scanner }\end{array}$ & Sensors & Low & Expensive \\
Device & & & \\
\hline $\begin{array}{l}\text { Capacitive } \\
\text { Scanner } \\
\text { Device }\end{array}$ & Capacitors & Medium & Expensive \\
\hline
\end{tabular}

b. Function of web Services system

Web services system play essential part of fetching information between cloud system and bank D.B \& sends it to the ATM machine that is utilized for establishing as an interface for the customers.

\section{c. Performance of GSM system}

The bank account information of customer is saved on cloud system in centralized way. The information of all bank accounts of bank account owner are shown. customer requires to choose one of the desire bank accounts for the transaction deals. If customer wants to send the money or debit the money from bank account, he/she will get One Time Password on registered mobile phone number. The GSM system created One Time Password for enforce verify $[13,14]$ transaction from the desire bank side.

This OTP requires to be entered for the transaction deal to be execute. Once the transaction is done system will return to home screen.



\section{Mathematical model and condition transition diagram}
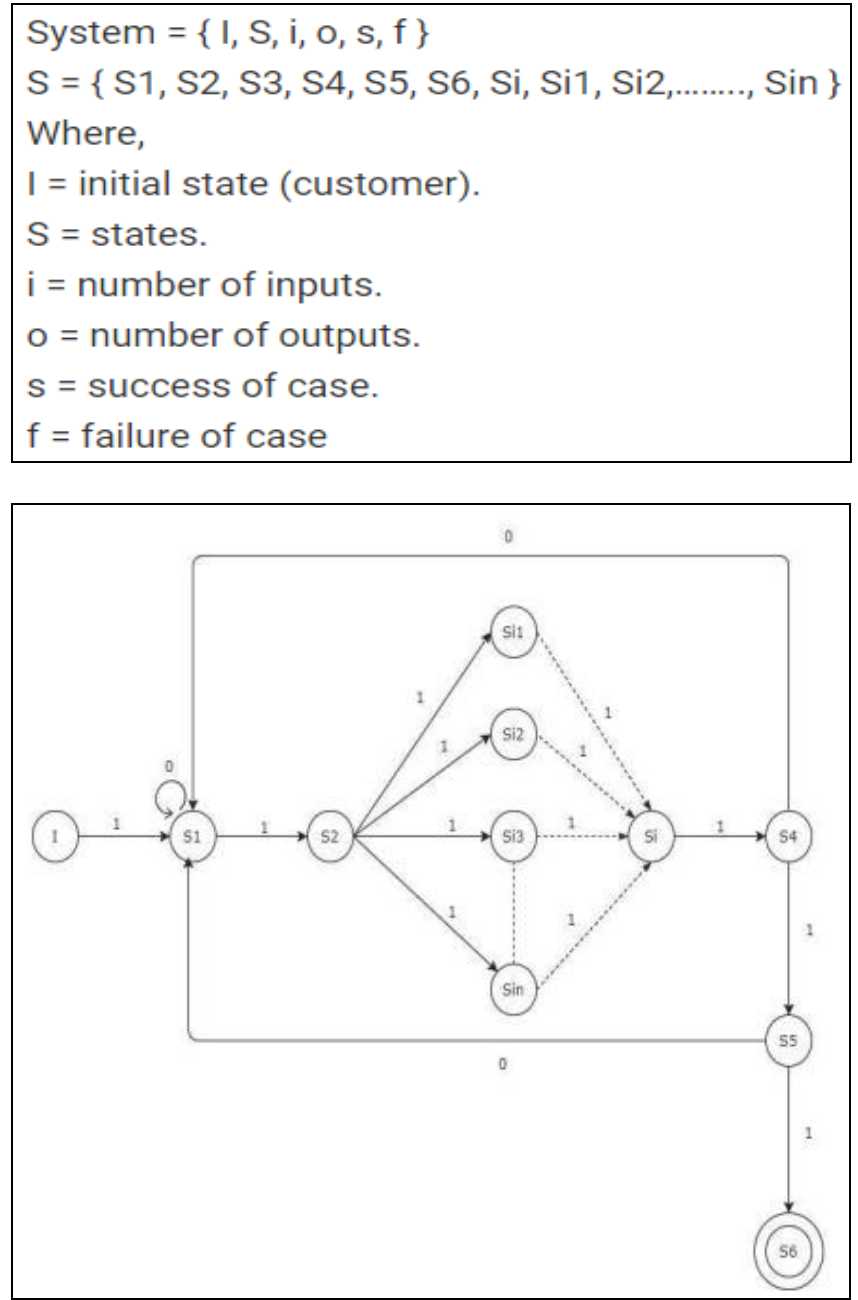

Fig 3: State Transition figure

\section{Benefits}

- All bank accounts of customer are run in a single touch thus not require to hold many ATM cards and remember their PINs.

- The proposed system is utilizing biometric rather of PINs for verification. Thus, the transaction deals become more secure.

- It suspends the cheat calls allied to the Automatic Teller Machine card identification and other all.

\section{Conclusion}

In the presented card-less multi-banking Transaction Automatic Teller Machine system, take place the standard ATM. It has benefits such as saves production expenses of ATM cards and reduces disadvantages of the standard ATM system like holding many ATM cards, losing of ATM card, disremembering PINs, memorized many ATM PINs, cheat 
calls linked to Automatic Teller Machine card, etc. and gives high level security by utilizing identification like as fingerprint and One Time Password system model; therefore making it simple to utilize many bank account transaction deals with single touch.

\section{References}

1. AK Jain, Nandakumar K, Nagar A. Biometric Template Security, ACM, 2008. DOl.10.1155/2008/579416.

2. Mohsin Karovaliya, Saifali Karedia, Sharad Oza, Dr. DR Kalbande, Enhanced Security for ATM machine with OTP and facial recognition features, International Conference On Advanced Computing Technologies and Applications I CATA, 2015.

3. Shier WA, Yanushkevich SN. "Biometrics in Human Machine Interaction," The International Conference On Information and Digital Technologies, 2015. http://biometrics.pbworks.com/f/comparisontable.png Last seen 02 Sept 2017

4. Joyce Soares, Gaikwad AN. A Self-Banking Biomtric M/C with Fake Detection Applied to Fingerprint and Iris along with GSM Tech. for OTP, International Conference on Communication and Signal Processing, April 6-8, India, 2016.

5. Samarth Bharadwaj, Mayank Vatsa, Richa Singh. Biometric quality a review of fingerprint, iris, and face, Bharadwaj et al. EURASIP Journal on Image and Video Processing, 2014. 34http://jivp.eurasipjournals.com/content/2014/1/34

6. Ekberjan Derman, Koray Gecici Y, Albert Ali Salah, Short Term Face Recognition For Automatic Teller Machine (Atm) Users," 978-1-4799-3343-3/13/\$31.00 (C)2013ieee.

7. Yun Yang, JiaMi, ATM terminal design is based on fingerprint recognition, 978-1-4244-6349 7/10/\$26.00 (C)201 0

IEEE. http://www.360biometrics.com/faq/fingerprint_scanner $\begin{array}{llll}\text { s.phpLast } & \text { seen } & 02 & \text { Sept2017 }\end{array}$ https://www.bayometric.com/fingerprint-readertechnologycomparison/ Last seen 02 Sept2017 http://www.biometric-solutions.com/fingerprintrecognition.html Last seen 02 Sept 2017

8. Joyce Soares, Gaikwad AN, Fingerprint and Iris Biometric Controlled Smart Banking Machine Embedded with GSM Technology for OTP, (ICACDOT), 2016.

9. Shweta Singh, Akhilesh Singh, Rakesh Kumar, A Constraint-based Biometric Scheme on ATM and Swiping Machine, International Conference on Computational Techniques in Information and Communication Technologies(ICCTICT), 2016.

10. Iwasokun Gabriel Babatunde, Munda Josiah Lange, Akinyokun Oluwole Charles, Dehinbo Johnson Olumuyiwa, Experimental Study of Thumbprint-Based Authentication Framework for ATM Machines, Science and Information Conference 2014 August 27-29, London, UK, 2014.

11. Shimal Sri Das, Debbarma Jhunu. Designing a Biometric Strategy (Fingerprint) Measure for Enhancing ATM Security in Indian E-Banking System, Ibidapo, O. Akinyemi, Zaccheous O. Omogbadegun, and Olufemi M. Oyelami (2010), "Towards Designing a Biometric Measure for Enhancing ATM Security in Nigeria eBanking System,'International Journal of
Electrical \& Computer Sciences IJECS-IJENS. 2011; 10(06):68-73.

12. Nair KK, Albert Helberg, Johannes van der Merwe an Apporach to Improve the Match-on-Card Fingerprint Authentication System Security, ISBN: 978-1-46739609-7, 2016. IEEE.

13. Lasisi H, Ajisafe AA, Development of stripe biometric based Fingerprint Authentications Systems in Automated Teller Machines, IEEE, ISBN. 978-1 -46732488-5, 2012, 172- 175.

14. Hamid Haqani, Mir Saleem, Shoaib Amin Banday, Ab RoufKhan, Biometric verified Access Control of Critical Data on a Cloud, International Conference on Communication and Signal Processing, April 3-5, India, 2014.

15. Nandakumar K. A Fingerprint Cryptosystem Based on Minutiae Phase Spectrum, WIFS, USA, pages, 2010.

16. Iwasokun Gabriel Babatunde, Munda Josiah Lange, Akinyokun Oluwole Charles, Dehinbo Johnson Olumuyiwa, Experimental Study of ThumbprintBasedAuthentication Framework for ATM Machines", Science and Information Conference August 27-29, 2014 | London, UK, 2014.

17. Michael Mireku Kwakye, Hanan Yaro Boforo, Eugene Louis Badzongoly, Adoption of Biometric Fingerprint Identification as an Accessible, Secured form of ATM Transaction Authentication",(IJACSA), 2014.

18. Abdul Razaque, Fathi H. Amsaad, Chaitanya Kumar Nerella, Musbah Abdulgader, Harsha Saranu, "MultiBiometric System Using Fuzzy Vault ", 978-1-46739985-2/16/\$31.00, 2016. IEEE

19. Debanjan Sadhya, Sanjay Kumar Singh, Bodhi Chakraborty, Review of key-binding-based biometric data protection schemes", IET Biom. (C) The Institution of Engineering and Technology, 2016.

20. JinXin $\mathrm{Xu}$ an Online Biometric Identification System Based on Two Dimensional Fisher Linear Discriminant”, 978-1- 4673-9098-9/15/\$31.00 (C)2015IEEE.

21. Sabout Nagaraju, Latha Parthiban Trusted framework for online banking in public cloud using multi-factor authentication and privacy protection gateway, Nagaraju and Parthiban Journal of Cloud Computing: Advances, Systems and Applications. 2015; 4:22.

22. Jebline GR, Gomathi S, A Novel Method to Enhance the Security of ATM using Biometrics, International Confernce on Circuit, Power and Computing Technologies [ICCPCT], 2015.

23. Imam, Muhammad, Jannat, Nabila, Bibi Farzana. Short Term Authentication of ATM Customers through Characteristics of Body and Face. 2019 International Conference on DATA SCIENCE Karachi (ICDS19), 2019, 1-7. http://icds19.jinnah.edu/proceedings.pdf.

24. Imam MY, Jannat N, Bibi F, Khan GS, Effective Study of Home plants in Purity of Territory by utilizing Wireless Sensor System," 2019 16th International Bhurban Conference on Applied Sciences and Technology (IBCAST), Islamabad, Pakistan, 2019, pp. 322-327. doi: 10.1109/IBCAST.2019.8667206

25. Imam Muhammad, Jannat Nabila, Bilal Suleman, Muhammad Rehman, Ayesha. Automatic Teller Machine Transaction Approach on the Basis of New era. International Journal of Scientific and Engineering Research. 2019; 10:24-27. 10.14299/ijser.2019.03. 